\title{
A Comparative Study on Emotional Intelligence and Mental Toughness for Visually Impaired Male and Female Athletes
}

\author{
Robabeh Rostami (Corresponding author) \\ Department of Physical Education and Sport Sciences, \\ School of Education and Psychology, Shiraz University, Shiraz, IR Iran. \\ E-mail: rostami@shirazu.ac.ir \\ Nahid Mohammadi \\ Department of Physical Education and Sport Sciences, \\ School of Education and Psychology, Shiraz University, Shiraz, IR Iran
}

Received: 20-09- 2015

Accepted: 28-10- 2015

Published: 31-10- 2015

doi:10.7575/aiac.ijkss.v.3n.4p.74

URL: http://dx.doi.org/10.7575/aiac.ijkss.v.3n.4p.74

\begin{abstract}
Background: Nowadays researches find that athlete's performance is affected not only by physical fitness, technical and tactical factors, but also mental and emotional features can affect sport performance. Objective: Hence, the aim of this study is examined the dimensions of emotional intelligence and mental toughness visually impaired male and female athletes. Methodology: This was a causal-comparative study, where the statistical population included 300 visually impaired male and female athletes taking part in the First National Cultural- Sports Festival featuring goalball, tug-of-war, track and field, swimming, and powerlifting. Using a smaple of convenience, 70 participants completed the Sheard, Golby, and van Wersch-questionnaire on mental toughness in three dimensions of "confidence" "control" and "constancy", and the Petrides and Furnham's questionnaire in four dimensions of " understanding emotions", " social skills" " controlling emotions" and " optimism". Results: Analysis of variables using an independent t-test showed significant differences in the dimensions of controlling emotions, understanding emotions, and social skills in favor of visually impaired sportswomen. However, there were no significant differences between the genders for optimism in the emotional intelligence questionnaire, and in mental toughness questionnaire. Conclusions: Visually impaired individuals pass through stages of emotional intelligence in a different way compared to those with normal vision. Moreover, motor skills and sports for the visually impaired are of a different kind. Moreover, our results showed that women benefited more from participating in physical and sporting activities than men did. Therefore, we recommend that authorities and people involved in sports for the visually impaired should make more use of exercises in psychological skills, along with technical and tactical ones, for visually impaired male athletes.
\end{abstract}

Keywords: Mental toughness, emotional intelligence, visually impaired athletes

\section{Introduction}

Disability is a set of physical or mental disorders that prevents individuals personally or socially from normal and independent life. This can be due to congenital, inherited, acquired disabilities and disorders (Rostami and Rezaee, 2014).Vision is the most dominant source of feedback used by humans and is therefore of extreme importance in day to day living. Impaired vision may be in the form of total vision loss or low vision. Visual impairment is maybe accompanied by psychological reactions, often involved in the emergence of psychological crises through causing anxiety, worry, lower self-confidence, and other psychological problems (REF). For almost half a century, Research activities have continued alongside the glory achieved by national visually impaired champions in domestic and international sports arenas, (Abbasi Tehrani and Dolatabadi, 2002).

Psychological factors are crucial for personal and social adaptation. On the other hand it is an influent implement for consistency of athlete performance and to conduct required attempts for controlling thoughts and emotions before performance (Rostami and Rezaee, 2014; Martin, Moritz and Hall, 1999). Available evidence shows some psychological skills are learned through interaction with other people. Acquisition of a large number of these skills requires vision, however due to their impairment, the visually impaired are limited in these experiences (REF). This can therefore influence the maturation of psychological skills such as mental toughness, emotional and social interaction (Ghomrani and Jafari, 2004). Emotional intelligence refers to understanding of one's own feelings and of its utilization when making suitable decisions in life. It is also the capability of managing mood and mental status and impulses. In fact, emotional intelligence is a factor contributing to motivation and hope in people when they fail to reach their desired goals, enabling them to understand themselves and others, establish suitable relationships with people, and adapt themselves to their environment (Rahmati and Naimi kia, 2012). According to Goldman (2003), emotional 
intelligence plays a substantial role in achieving success in daily life. As a form of social intelligence, emotional intelligence is a good predictor of efficiency in special domains such as job and educational performance. It encompass the ability to control one's own and other people's feelings and emotions, to distinguish them from each other, and to utilize this ability for guiding one's thoughts and modes of action (Mami and Vahidi, 2013).

Few studies have been carried out on emotional intelligence in non-athletic visually impaired males and females. In these studies, the females perform better than males (Bigdeli and Elahi, 2014; Shafieitabar, Khodapanahi, and Sedghpour, 2008), which do not corroborate. Those found in the research carried out by Hosseinian and Emamipour (2006) and Beirami, Gharibi, Hashemi, and Ghloizadeh (2010). Here, the non-athletic visually impaired females obtained lower scores in emotional intelligence compared to the males. In fact, the males were superior in selfmotivation, self-control, and social skills. Moreover, in research conducted by Alirezaei Moghaddam Bejestani and Farid Asghar nezhad (2012), no significant differences were observed between the micro scales of emotional intelligence among the three groups of blind, low-vision and normal people.

Mental toughness is another construct related to organizing and managing emotions (Connaughton, Wadey, Hanton, and Jones, 2008). Jones (2002) defined mental toughness as having concentration, self-confidence, control, resoluteness, and fighting spirit under stressful conditions of competitions and training. Mental toughness is one of the personality traits contributing to promotion of health. In fact, a combination of beliefs held by individuals about themselves and the world protect them against internal and external pressures. Mental toughness is a factor that helps individuals pull through difficult situations and successfully overcome threatening conditions (Jomhari, 2002). Studies carried out in this regard have shown that men are superior to women in mental toughness and its dimensions (Farrokhi, Kashani, Motesharrei, 2011; Nicklaus, Pullman, Levi, and Bacchus, 2009). Considering what was discussed above, it can be concluded that characteristics of mental toughness are closely tied with those of emotional intelligence (Maddi, 1990; Barton, quoted by Khademi, 2011).

Psychological factors related to sports performance have long been attracting the interest of trainers, athletes, and sport psychologists (Gucciardi and Jones, 2009). Top-notch trainers and athletes believe that successful athletes are not necessarily those with better physical preparedness, tactics, and specialized skills. What distinguishes athletes from each other is their psychological skills and preparedness (Loehr, 1982; quoted by Khademi, 2011). The competitive nature of sports encompasses a wide range of emotions including anger, fear, hopelessness, anxiety, feelings of inferiority, pride, sadness, and happiness, all of which influence the performance of individuals (Botterill and Brown, 2002; Jones, 2002). Hence, it is essential to instruct disable athletes' psychological skills beside physical skills with the aim of using its advantages. Athletes should be aware of advantages of psychological skills interventions and its effects on performance and emotions control (Rostami and Rezaee, 2014). The dimensions of psychological preparedness are important for success in sports, especially at high levels (Moran, 2004; quoted by Khademi, 2011). Furthermore, research efforts in this field have not been conducted on the visually impaired community, especially in Iran. Therefore, the necessity and importance of carrying out such studies for educating and preparing athletes warranted so that they can suitably manage stressful obstacles and reach their potential. Therefore, this study intended to determine the differences in mental toughness and emotional intelligence between visually impaired male and female athletes who took part in the First National Cultural- Sports Festival.

\section{Methodology}

\subsection{Population and sampling}

This was a causal-comparative study, where the statistical population consisted of 300 visually impaired male and female athletes taking part in the First National Cultural-Sports Festival in goalball, tug-of-war, track and field, swimming, and powerlifting. Using a convenient sampling, 70 athletes were selected.

\subsection{Instrument and procedure}

First all participants signed consent form and then complete the Personal Information Questionnaire and the Petrides and Furnham Questionnaire (2003), which contained 30 items on a 7-point Likert Scale with a range of 1-7 in the four dimensions of understanding emotions, social skills, controlling emotions, and optimism. They also filled out the Sheard, Golby, and van Wersch Questionnaire (2009) in the three dimensions of confidence, control, and constancy. The reliability and validity of these questionnaires have been confirmed, using the Cronbach's alpha for the micro scales of confidence, constancy, and control in the mental toughness questionnaire being 0.80, 0.74, and 0.71, respectively (Sheard, Golby, van Wersch, 2009). Khademi (2011) reported that the overall Cronbach's alpha for this questionnaire was 0.73 . Similarly, it was $0.78,0.71$, and 0.56 for the micro scales of confidence, constancy, and control, respectively. Furthermore, Farrokhi, Kashani, and Motasharei (2011) showed the intraclass correlation coefficient of the micro-scales varied from 0.78 to 0.85 , and Cronbach's alpha from 0.73 to 0.83 (which showed an acceptable reliability for the questionnaire). Cronbach's alpha for emotional intelligence was reported to be 0.85 in the research conducted by Ahmadi Azghandi et al. (2006) and 0.81 in the study carried out by Marnani (2003) (quoted by Ali Akbari Babukani, 2014).

\section{3 data analysis}

In the current study, central tendency and dispersion parameters such as mean and standard deviation were used to describe the data. Moreover, the independent t-test was employed for inferential analysis to compare differences in the 
dimensions of emotional intelligence and mental toughness between visually impaired male and female athletes. The significance level was $\mathrm{p} \leq 0.05$ and SPSS 22 was used for all processes of data analysis.

\section{Results}

Tables 1 showed that, the mean scores of visually impaired female athletes for all dimensions of emotional intelligence, and for the dimensions of confidence and constancy in mental toughness, were higher compared to those for male visually impaired athletes, but the scores of the visually impaired male athletes were higher in the control dimension of mental toughness.

Table 1. Distribution of means and standard deviations related to the dimensions of emotional intelligence and mental toughness in visually impaired male and female athletes

\begin{tabular}{ccccccccc}
\hline & & \multicolumn{3}{c}{ Dimension of Emotional Intelligence } & \multicolumn{2}{c}{ Dimension of Mental Toughness } \\
\cline { 3 - 9 } Gender Variable & & $\begin{array}{c}\text { understanding } \\
\text { emotions }\end{array}$ & $\begin{array}{c}\text { social } \\
\text { skills }\end{array}$ & $\begin{array}{c}\text { controlling } \\
\text { emotions }\end{array}$ & optimism & confidence & control & constancy \\
\multirow{5}{*}{ Female } & $\mathrm{N}$ & 35 & 35 & 35 & 35 & 35 & 35 & 35 \\
& $\mathrm{M}$ & 55.20 & 28.19 & 30.22 & 35.71 & 18.22 & 6.71 & 9.03 \\
& $\mathrm{SD}$ & 6.08 & 6.28 & 7.69 & 7.44 & 3.80 & 2.30 & 3.22 \\
& $\mathrm{~N}$ & 35 & 35 & 35 & 35 & 35 & 35 & 35 \\
Male & $\mathrm{M}$ & 49.76 & 26.28 & 24.99 & 34.34 & 17.49 & 6.41 & 10.25 \\
& $\mathrm{SD}$ & 5.76 & 4.75 & 6.76 & 6.72 & 3.17 & 1.61 & 4.52 \\
\hline
\end{tabular}

Table 2 illustrated that there were significant differences between the visually impaired male and female athletes in the dimensions of understanding emotions, social skills, and controlling emotions, but there were no significant differences between them in the dimensions of mental toughness. In other word, considering table 1, women had better performance in these aspects rather than men.

Table 2. Results of the independent t-test related to the dimensions of emotional intelligence and mental toughness in visually impaired male and female athletes

\begin{tabular}{ccccc}
\hline & Mean Difference & $\mathrm{t}$ & $\mathrm{df}$ & Sig \\
\hline understanding emotions & 5.44 & 3.84 & 68 & $* 0.000$ \\
controlling emotions & 5.23 & 3.02 & 68 & $* 0.004$ \\
social skills & 3.90 & 2.94 & 68 & $* 0.005$ \\
optimism & 1.37 & 0.70 & 68 & 0.486 \\
confidence & 0.73 & 0.88 & 68 & 0.382 \\
constancy & 0.29 & 0.62 & 68 & 0.539 \\
control & 1.22 & 1.30 & 68 & 0.198 \\
\hline
\end{tabular}

\section{Discussion}

This study intended to examine the dimensions of emotional intelligence and mental toughness in visually impaired male and female athletes. Results showed there were significant gender differences in the three dimensions of understanding emotions, controlling emotions, and social skills, but there were no significant gender differences in the dimension of optimism or in the dimensions of mental toughness. Results of this study and the high scores of visually impaired female athletes compared to visually impaired male athletes are consistent with other studies such as those conducted by Bigdeli and Elahi (2014), and Shafieitabar et al (2008), who showed that women without vision disability were superior to visually impaired female athletes with respect to the dimensions of emotional intelligence.

The results also indicated that the three dimensions of understanding emotions, controlling emotions, and social skills are more important than the other dimension of emotional intelligence for the performance of these visually impaired athletes, even though they are inconsistent with the results of studies by Hosseinian and Emamipour (2006) and Beirami et al (2010). They found that visually impaired female athletes received lower scores compared to visually impaired male athletes in the components of emotional intelligence, and that the visually impaired male athletes scored higher in the components of emotional intelligence (self-motivation, self-control, and social skills). Furthermore, contrary to results of research conducted by Farrokhi et al (2011) and Nicklaus et al. (2009), in which they concluded visually 
impaired male athletes were superior to visually impaired female athletes in mental toughness and its components, the results of the current study did not show any significant differences between visually impaired male and female athletes in the three dimensions of mental toughness. These results are inconsistent with those found by Subramanya, Singh, and Yadav (2011). They observed visually impaired female athletes were superior to visually impaired male athletes in controlling negative energy. In general, the current findings do not conform to those observed in research conducted by Maddi (1990) and Barton (2006). They observed there were significant differences in all dimensions of emotional intelligence and mental toughness, and reported these two factors were correlated.

Moreover, various factors such as status, history of previous achievements, level of competition, age, nature of the sport, and individual differences are involved in the desirable shaping of mental toughness and emotional intelligence. Visually impaired male and female athletes may have used similar strategies to overcome obstacles and achieve success. The results of this research confirm the view that inclination towards sports and physical activities somehow enhances emotional intelligence and prepares the ground for achieving success in various social and family domains and for their making progress in sports. In fact, it can be argued that participation in sporting activities increases athletes' skills and improves their social health. Furthermore, physical and tactical abilities and specialized skills are not the only guarantee for achieving success nowadays (Mayer, 1997). Additionally, psychological preparedness is one of the factors contributing to success, preparing athletes for competitions and teaching them how to react when confronted with various processes.

Sensory deficits including visual impairment, which is divided into two classes of vision loss and low vision, afflicts a considerable percentage of people living in any society. Considering the fact that emotional and social skills are learned through communicating with others, and since eyesight is required in the acquisition of many of these skills, visually impaired people seem to be deprived of acquiring such experiences, which can greatly affect their emotional maturation and interactions. However, participation in sports has been considered as a factor contributing to social interactions of individuals, especially visually impaired people.

Considering the findings of this research and the importance of the crucial role of mental toughness and emotional intelligence, it can be expected that the performance of athletes can be enhanced through greater awareness of these components (Zareh, 2002; Samari and Tahmasbi, 2007). It is suggested that further research using various and larger statistical populations should be conducted to compare mental toughness and emotional intelligence more accurately. Further this research conducting such studies can enlighten researchers and the sporting community in the country about how visually impaired athletes is prepared. In addition, it is essential to set the ground for offering necessary training to upgrade these skills and improve the performance of these athletes. Therefore, by conducting such studies, which can improve the performance of athletes at low cost, there will be better performance in the communities of visually impaired athletes. Nowadays, competition is no longer limited to superior techniques, but successful athletes enjoy greater psychological preparedness. It is essential that consider and schedule substantial psychological intervention programs for this group of athletes. This also sounds imperative to have a sport psychologist for players while practicing and competing.

\section{Acknowledgements}

We would like to express our deep gratitude to all athletes participating in the Festival, who cheerfully helped us collect the necessary.

\section{References}

Abasi Tehrani, F., \& Dolatabadi, S. (2002). An investigation of the Depression and anxiety in The visual disabilities of 50-16 years in Tehran on the base of age, gender, disability, marital status, employment status. Research on Exceptional Children, 6(4), 359-376.

Ali akbari Baboukani, M. (2014). The Prediction Of Sport Achievement on The Base of Emotional Intelligence, Cognitive Intelligence and Mental Toughness on Female Athletes Individual and Team Sport. Unpublished Master's Thesis. Shiraz University.

Alirezaee Moghaddam Bajestani S, \& Asghar Asgharnejad Farid A. (2012). The comparison of Emotional intelligence among the three Groups of the Blind, Low vision and the Normal ones. Journal of Exceptional Education, 4(112), 2736.

Beirami M., GHarib H., Hashemi T., \& GHoliZadeh Z. (2010). Predicting Students' Emotional in Intelligence Base on Deographic Factors. Quarterly Andisheh va Raftar (Applied Psychology), 4(14), 57-64.

Bigdelie E, \& Elahi, T. (2014). Study and Comparison of Emotional Intelligence among High- School Blind and Deaf Students. journal of Exceptional Education, 4(126), 22-31.

Botterill, C., \& Brown, M. (2002). Emotion and perspective in sport. International Journal of Sport Psychology, 33(1), 38-60.

Connaughton, D., Wadey, R., Hanton, S., \& Jones, G. (2008). The development and maintenance of mental toughness: Perceptions of elite performers. Journal of Sports Sciences, 26(1), 83-95. 
Farrokhi A., Kashani V., \& Motasharei E. (2011). Comparison of Mental Toughness of Contact and Non-Contact Men and Women Athletes in Different Skill Levels. Semi-Annually Motor Behavior (Research on Sport Science), 3(8), 7186.

Ghomrani, A., \& Jafari, H. R. (2004). Introduction to Emotional Intelligence and blindness. Journal of Exceptional Education(31), 25-30.

Gucciardi, D. F., \& Jones, M. I. (2012). Beyond optimal performance: Mental toughness profiles and developmental success in adolescent cricketers. Journal of Sport and Exercise Psychology, 34(1), 16.

Hosainian, S., \& Emamipur, S. (2006). Comparing Emotional Intelligence and Assertiveness in Normal and Blind Boys and Girls. journal of Applied Psychology, 1, 19-29.

Jamhari،F. (2002). Survey the relationship between hardiness and propensity to anxiety and depression among men and women students of universities of Tehran.Doctoral dissertation General Psychology. University of AllamehTabataba of Tehran.

Jones, G. (2002). What is this thing called mental toughness? An investigation of elite sport performers. Journal of applied sport psychology, 14(3), 205-218.

Khademi, E. (2011). The Prediction Of Psychological Toughness on The base of Psychological Skill by The Mediation of Emotional Intelligence. Unpublished Master's Thesis. Shiraz University.

Maddi, S. R. (1990). Issues and interventions in stress mastery. Personality and disease, 121-154.

Mami, S., \& Vahidi, A. (2013). Relationship between Conventional intelligence and emotional intelligence with mental health of Ilam Azad University students. Humanities research of Esfahan university, 4(20), 59-76.

Martin, K. A., Moritz, S. E., \& Hall, C. R. (1999). Imagery use in sport: a literature review and applied model. The sport psychologist, 13(3), 245-268.

Mayer, J. (1997). What is emotional intelligence?, in P Salovey \& DJ Sluyter (eds.), Emotional development and emotional intelligence, Basic Books, New York, NY.

Nicholls, A. R., Polman, R. C., Levy, A. R., \& Backhouse, S. H. (2009). Mental toughness in sport: Achievement level, gender, age, experience, and sport type differences. Personality and Individual Differences, 47(1), 73-75.

Rahmati, F., \& Naimi Kia, M. (2012). The relationship between emotional intelligence and psychological hardiness in athlete and non-athlete students. Journal of Sport Management and action dehavior, 11(22), 141-148.

Rostami, R., Mohammadhasani, F., \& Ajam, M. (2014). The Effect of Disability Classification on Mental preparation in Disabled Female Basketball Players. Poster session presented at the 3th Iranian International Conference on Women's Health 2014.

Rostami, R., \& Rezaee, M. (2014). Correlation between General Health and Quality of Life in Caregivers of Veterans with Spinal Cord Injury. Quarterly of Iranian Journal of War \& Public Health, 6(3), 87-93.

Samari, A. A., \& Tahmasebi, F. (2007). The study of correlation between emotional intelligence and academic Achievement in Students. The Quarterly Journal of Fundamentals of Mental Health, 9(35\&36), 121-128.

Shafietabar, M., Khodapanahi, M. K., \& Sedghpour, S. (2008). An investigation of the relation between emotional intelligence and five factors of personality in students. Journal of Behavioral Sciences, 2(2), 173-182.

Sheard, M., Golby, J., \& van Wersch, A. (2009). Progress toward construct validation of the Sports Mental Toughness Questionnaire (SMTQ). European Journal of Psychological Assessment, 25(3), 186-193.

Subramanyam, V., Singh, K., \& Yadav, G. (2011). A comparative study of gender differences on mental toughness among senior national athletes. Indian Journal of Movement Education and Exercises Sciences (IJMEES), Bi-annual Refereed Journal, 2 (2).

Zare, M. (2002). The study of correlation between emotional intelligence and academic Achievement in Students. Dissertation for master degree. University of Allamehtabatabai. Tehran. 